\title{
Development of Combined Diamond-impregnated Lapping Plates
}

\author{
Ming-Yi Tsai, ${ }^{*}$ Yue-Feng Lin, and Guan-Fu Lin \\ Department of Mechanical Engineering, National Chin-Yi University, \\ Zhongshan Rd., Taiping Dist., Taichung 41170, Taiwan
}

(Received March 28, 2018; accepted August 27, 2018)

Keywords: single-crystal silicon, diamond grinding wheel, resin, ceramic, lapping

Single-crystal silicon carbide $(\mathrm{SiC})$ wafers for use in semiconductor chip production are a next-generation material. $\mathrm{SiC}$ will be the power-saving, high-energy-transforming, and hightemperature working element of the future. However, $\mathrm{SiC}$ is a very difficult material to process because of its exceptional hardness and chemical stability. Conventional polishing takes an enormous amount of time, and is inefficient and very costly. An improved process is urgently needed to reduce cost and raise efficiency. In this paper, we present a diamond lapping wheel for $\mathrm{SiC}$ to improve the material removal rate. Four kinds of diamond wheel were fabricated using two types of binder material (resin and ceramic) and two sizes of diamond (1 and $6 \mu \mathrm{m}$ ). The surface roughness and material removal rates of $\mathrm{SiC}$ wafer samples, using each of the diamond laps, were investigated. The experimental results showed that the rate of material removal using the ceramic wheel binder was higher than that using the resin-bound wheels. In addition, the ceramic diamond wheel gave a better surface finish. These results clearly indicated that the diamond laps were effective and could be used for SiC lapping.

\section{Introduction}

Single-crystal silicon carbide $(\mathrm{SiC})$ is a new high-power material that can be used for chip production. It has several very important features that make it superior to other materials in many applications. For example, it has outstanding thermal conductivity, high saturated electron drift velocity, high dielectric strength against field collapse, high mechanical strength, and excellent chemical stability. However, the high strength and chemical inertness make $\mathrm{SiC}$ very difficult to grow. The hardness and strength of $\mathrm{SiC}$ also make it very useful as an abrasive and for cutting tools. SiC was also used in the LED industry during early development. Flattening a wafer of $\mathrm{SiC}$ has always been problematic. Nowadays, this is usually done with free abrasive slurry against a copper or cast-iron lapping plate. However, this method is not very efficient, takes a long time, and the cost is high. The usual process is as follows. 1) Initial double-side grinding with cast-iron plates and $\mathrm{B}_{4} \mathrm{C}$-free abrasive, 2) single-side grinding with a copper plate and $6 \mu \mathrm{m}$ diamond slurry, and 3) final polishing with a resin-copper combined

*Corresponding author: e-mail: mytsai@ncut.edu.tw https://doi.org/10.18494/SAM.2018.2057 
plate and 1-3 $\mu \mathrm{m}$ diamond slurry. The complete process takes $6 \mathrm{~h}$ or more. The removal of a material during flattening with a hard plate and free abrasive entails three-body wear in which material is removed by abrasive particles rolling and sliding in the slurry between the SiC wafer and the hard plate. Harsha and Tewari proposed that the material removal rate in threebody wear is one-tenth of that achievable in two-body wear. ${ }^{(1)}$ The low processing efficiency is due to the fact that the abrasive particles spend $90 \%$ of the time rolling and only $10 \%$ sliding. Several important studies have recently been carried out on diamond abrasive grinding. ${ }^{(1)}$ Huo et al. proposed a method for grinding hard and brittle materials with nanodiamond grinding wheels with \#600, \#2000, and \#12000 diamond particles in a 350-mm-diameter ceramic-bonded wheel rotating at $2000 \mathrm{rpm} / \mathrm{min}$. Deionized (DI) water was used in the grinding slurry. ${ }^{(2)}$ Experimental results showed a flatness of $1 \mu \mathrm{m}$ and surface roughness $(R a)$ of $0.42 \mathrm{~nm}$ on a 508-mm-diameter SiC wafer. This result clearly showed that double-side grinding could replace mechancial polishing. ${ }^{(2)}$ Gao et al. proposed that although diamond abrasive grinding is the most common method used in silicon wafer manufacture, edge-cutting is always needed to dice the wafer. ${ }^{(3)}$ This study was mainly an investigation of the edge-cutting of silicon wafers with a diamond grinding wheel. Experimental parameters were $\# 600, \# 2000$, and $\# 3000$ mesh with both up-grinding and down-grinding. The size of abrasive particles, feed rate, and wafer thickness influenced the crack effect of the blade. Critical thickness results showed it to be higher in up-grinding than in down-grinding. Smaller abrasive particles and a lower feed rate could reduce cracking at the cutting edge, but with thicker wafers, the cutting crack size in down-grinding was larger than that in up-grinding. ${ }^{(3)}$ Chen et al. used arc diamond grinding wheels in a dressing process to investigate wear. ${ }^{(4)}$ They then studied the efficiency of different abrasives and bonding agents on the arc grinding wheel dressing process. The convex nonspherical $\mathrm{SiC}$ formed using dressed arc diamond grinding wheels revealed that dressing with both the resin and metal bonding agents was very efficient and accurate. The shape error of the arc grinding wheel was $2.5-6 \mu \mathrm{m} / 3 \mathrm{~mm}$, which meant a $90 \%$ reduction in shape error. In addition, the diamond abrasives were distributed more evenly in the arc grinding wheels, and sharper diamond points were exposed after dressing. The result of $\mathrm{SiC}$ flatness experiments was a $R a P V$ of $507 \mathrm{~nm}$ and $R a$ of $57.1 \mathrm{~nm} .{ }^{(4)}$ Kim et al. used a sapphire wafer to estimate the rate of material removal by lapping. ${ }^{(5)}$ Their three-body wear model comprised a diamond slurry on metal resin-bound lapping plates made of copper, aluminum, or zinc powder. Metal-resin plates combined with abrasives were also used. Two-body wear experiments were also conducted using fixed diamond abrasives in the platen dressed with a low concentration of $\mathrm{Al}_{2} \mathrm{O}_{3}$ slurry. Extensive tests were carried out, the basic purpose of which was to find the optimum lapping process for sapphire wafers. Lapping was carried out under different loads, rotation speeds, and times. The $R a$ values obtained using $9 \mu \mathrm{m}$ diamond abrasives with a copper-resin, aluminumresin, zinc-resin, and fixed diamond plates were $38.03,25.28,19.03$, and $69.50 \mathrm{~nm}$, respectively. ${ }^{(5)}$ Velden mentioned in his report that 3M Company used polishing pads with fixed abrasives and that a nonpolishing slurry chemical mechanical polishing (CMP) was used. ${ }^{(6)}$ The polishing pad was impregnated with abrasives, which promoted grinding efficiency, and the surface flatness was three times better than in a free-abrasive process. ${ }^{(6)}$ Enomoto et al. proposed a traditional grinding model with free abrasives that seriously damaged the enviroment and also increased 
the cost. ${ }^{(7)}$ They investigated a fixed abrasive grinding model and developed a spiral structured fixed oxide ceria abrasive polishing pad that actually decreased damage to the enviroment. ${ }^{(7)}$ Puttick et al. found that there was a transition from the brittle to the ductile mode in the singleedge cutting of single-crystal silicon material. ${ }^{(8)}$ This phenomenon occurred at a critical cutting thickness. In other words, at some stage, the mechanism of cutting was plastic deformation, not brittle fracture. $^{(8)}$ Bifano et al. proposed a plastic deformation theory for hard-brittle material and revealed that the energy of ductile grinding was lower than that for brittle fracture at a specific critical depth. ${ }^{(9)}$ This meant that the material removal mechanism was ductile grinding and that decreasing the cutting depth could transform brittle grinding to ductile grinding. This reduced the depth of damage, as well as surface roughness, resulting in a finer polish. ${ }^{(9)}$ Oliver et al. established a CMP model. ${ }^{(10)}$ They mentioned that abrasives were removed by adhesion onto the fibers of the polishing pad fabric. Their experiments showed there was a linear relationship between surface roughness and material removal rate within a certain range. ${ }^{(10)}$ Zhang et al. used a new type of ultraprecise diamond grinding wheel to polish cadmium-copper nanofilm. ${ }^{(11)}$ Their results showed non-subsurface damage and an undeformed nanocutting intersecting surface where the depth of deformation was $25-28 \mathrm{~nm} .{ }^{(11)}$

We present a diamond grinding wheel for $\mathrm{SiC}$ wafers with excellent material removal rate. Four kinds of diamond grinding wheel were fabricated for the experiments. Two binder materials (resin and ceramic) and two diamond sizes $(1$ and $6 \mu \mathrm{m})$ were used. The surface roughness of lapped $\mathrm{SiC}$ wafers was investigated, as well as the material removal rate, using each of the diamond grinding wheels.

\section{Experimental Setup}

Figure 1 is a flow diagram of the steps used in the fabrication of the diamond lapping plates. The process was as follows. (1) The bonding agent (resin or ceramic) and diamond abrasive

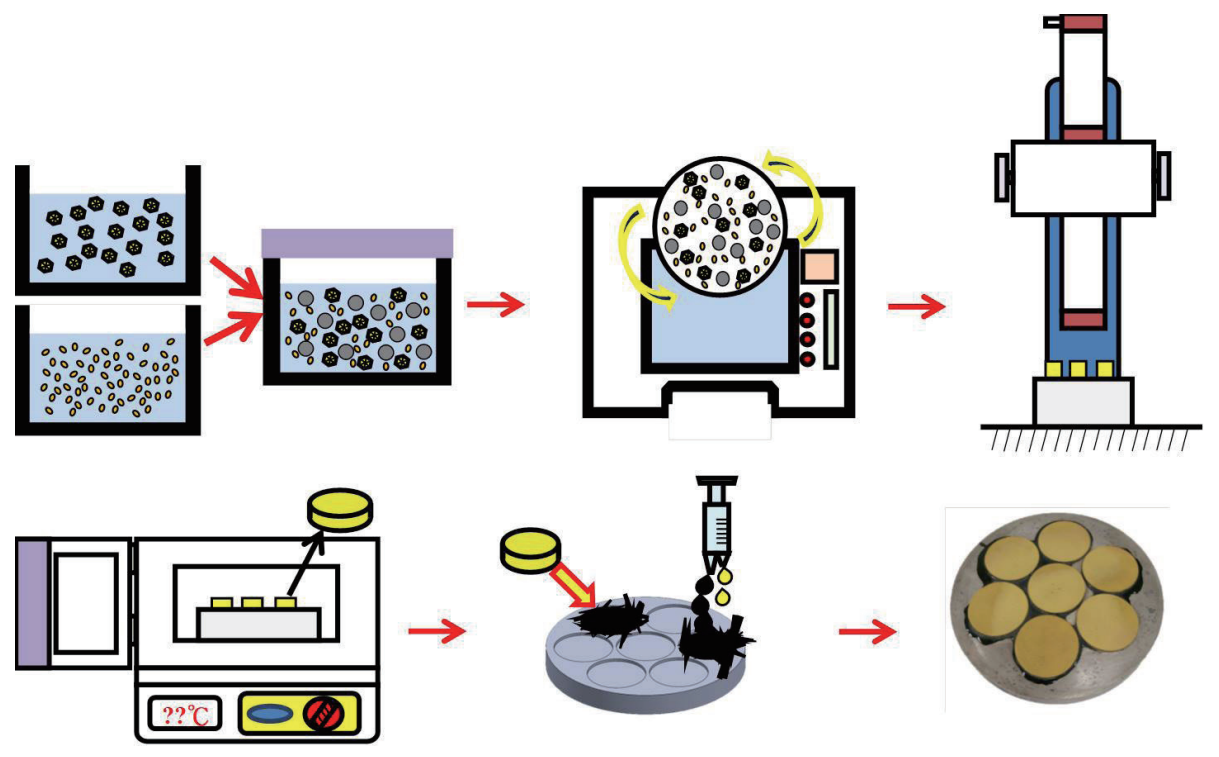

Fig. 1. (Color online) Making a diamond lapping plate. 
were prepared and mixed. (2) The abrasive mixture was placed in the mold and compressed at high temperature and pressure to form an abrasive pad $38 \mathrm{~mm}$ in diameter and $7 \mathrm{~mm}$ in thickness. (3) The aluminum plate to hold the lapping pads was machined from 7075 aluminum alloy, the dimensions of which are shown in Fig. 2. The seven milled recesses were $2 \mathrm{~mm}$ deep, leaving $5 \mathrm{~mm}$ protrusions of the abrasive pads. (4) The pads were fixed into the recesses using epoxy resin adhesive, and heat and pressure were applied to cure the adhesive. Four different lapping plates were fabricated (Table 1). Resin_6 and Resin_1 comprised 6 and $1 \mu \mathrm{m}$ diamond grit in the resin binder; Ceramic_6 and Ceramic_1 comprised 6 and $1 \mu \mathrm{m}$ diamond in the ceramic binder.

Figure 3 shows the following experimental process. (1) Four different lapping plates were fabricated as shown in Fig. 1. A basic analysis of physical characteristics, including the hardness and surface characteristics, was carried out. Hardness was measured using a Rockwell hardness tester in accordance with ASTM B294. A diamond pyramid was used at a load of 60 kg. SEM was carried out to observe surface characteristics. (2) The dressing procedure is very important to ensure the preparation of lapping plates with flat surfaces. The diamond dresser used was a brazed diamond disk made by Kinik Company and has diamond grit sizes of 120 $150 \mu \mathrm{m}$. The parameters used for dressing were a loading pressure of $5 \mathrm{kgf}$, a dresser clockwise
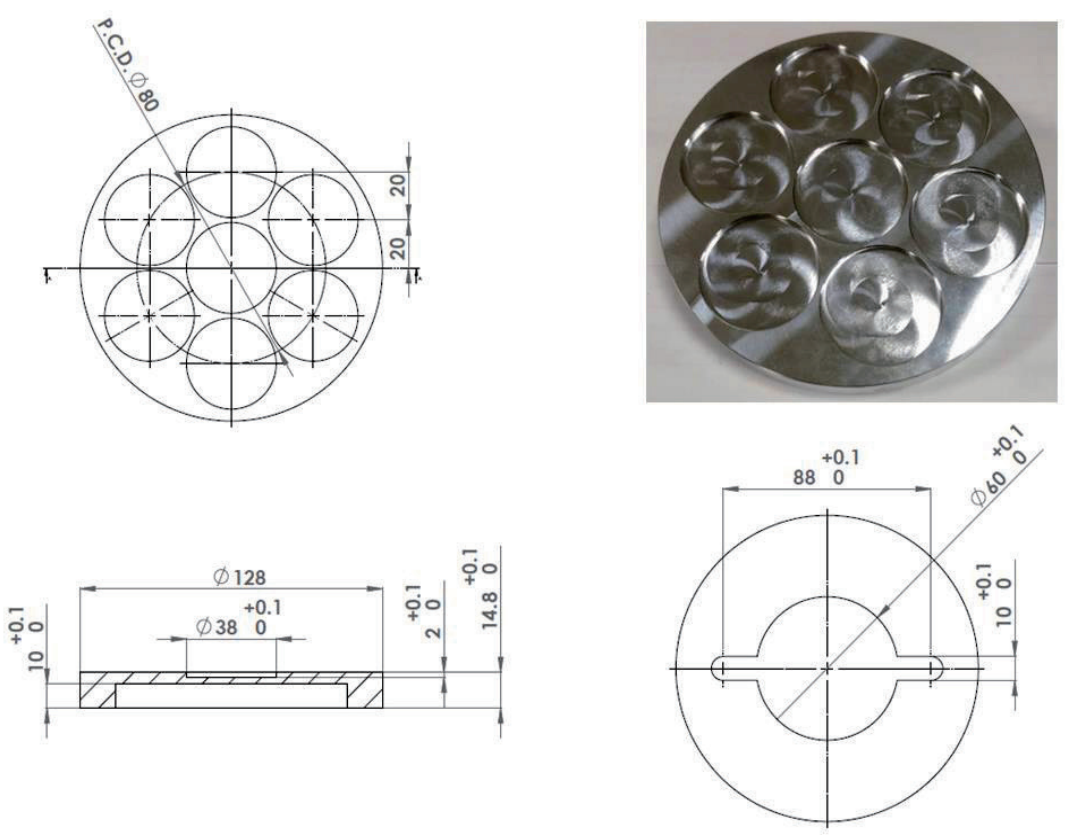

Fig. 2. Design of the lapping plate.

Table 1

Compositions of the four lapping plates.

\begin{tabular}{lcc}
\hline Lapping plate ID & Binder & Diamond grit $(\mu \mathrm{m})$ \\
\hline Resin_6 & Resin & 6 \\
Resin_1 & Resin & 1 \\
Ceramic_6 & Ceramic & 6 \\
Ceramic_1 & Ceramic & 1 \\
\hline
\end{tabular}




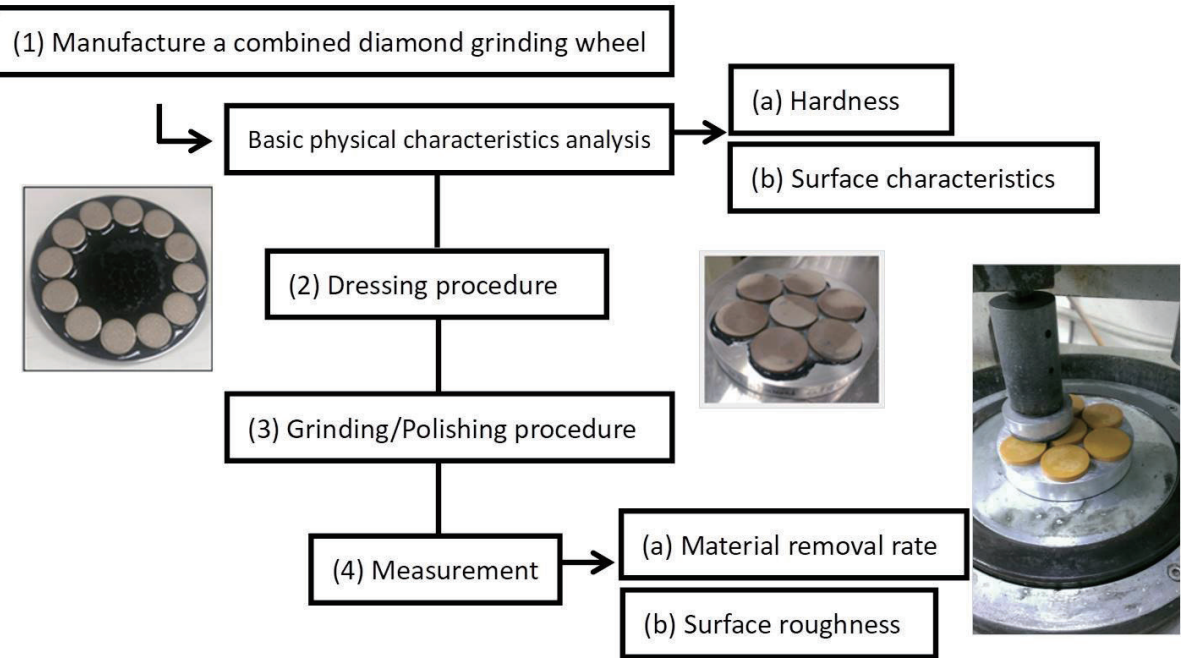

Fig. 3. (Color online) Experimental process.

rotation speed of $100 \mathrm{rpm}$, a lapping plate clockwise rotation speed of $20 \mathrm{rpm}$, dressing time of $15 \mathrm{~min}$, and a DI water flow rate of $250 \mathrm{~mL} / \mathrm{h}$. (3) Unground SiC wafers 2 " in diameter and $4^{\circ}$ sliced were used. The experimental parameters were a loading pressure of $2 \mathrm{kgf}$, a wafer holder clockwise rotation speed of $100 \mathrm{rpm}$, a lapping plate clockwise rotation speed of $20 \mathrm{rpm}$, a dressing time of $15 \mathrm{~min}$, a lapping time of $1 \mathrm{~h}$, and a DI water flow rate of $150 \mathrm{~mL} / \mathrm{h}$. (4) The final step was the measurement of the material removal rate and surface roughness. Figure 4 shows the nine measuring points used on each $\mathrm{SiC}$ wafer. The surface roughness was measured using a ZYGO 3D profiler. In operation, the surface of the $\mathrm{SiC}$ wafer was brought into focus and the objective was then adjusted to give an interference pattern on the screen. Measurements were carried out from left to right at intervals of $8 \mathrm{~mm}$ in the $X$ direction and $5 \mathrm{~mm}$ in the $Y$ direction.

\section{Results and Discussion}

\subsection{Dressing rate}

Dressing rate is one of the most important factors influencing the surface condition and the cost of a grinding or lapping tool. The amount of grinding surface that is removed per unit time is referred to as the dressing rate and is measured in $\mu \mathrm{m} / \mathrm{min}$ and computed from the amount of grinding surface removed divided by the time taken. Figure 5 shows the variation in dressing rate between the four different lapping plates. The dressing rate of Ceramic_6, about $2.8 \mu \mathrm{m} /$ min, is higher than that of Resin_6, which has a dressing rate of around $1.4 \mu \mathrm{m} / \mathrm{min}$. Also, the dressing rate of Ceramic_1, about $0.8 \mu \mathrm{m} / \mathrm{min}$, is higher than that of Resin_1, which is about $0.5 \mu \mathrm{m} / \mathrm{min}$. It can be seen that in the case of $6 \mu \mathrm{m}$ diamond grit, the dressing rate of the plates that have pads with the ceramic binder was about twice that of the resin-bonded plate. To 


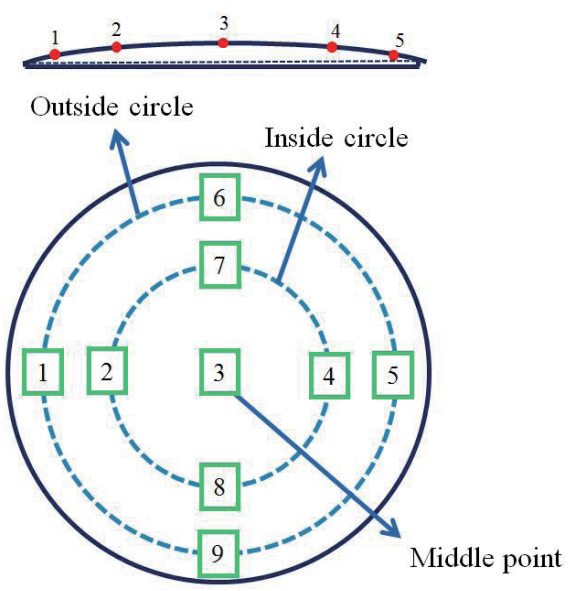

Fig. 4. (Color online) Position of the measuring points on the $\mathrm{SiC}$ wafers.

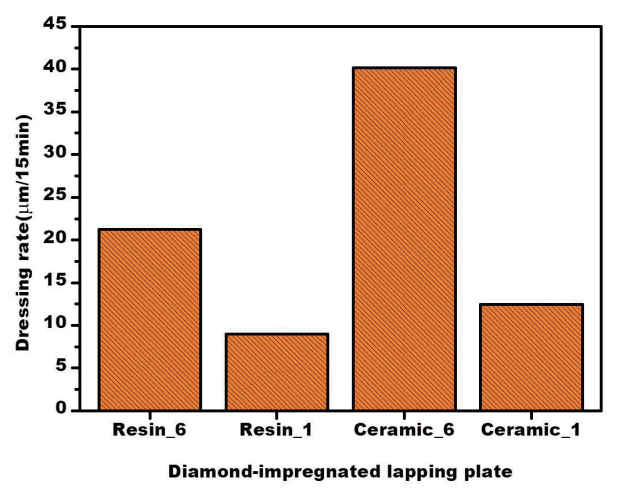

Fig. 5. (Color online) Dressing rate of diamondimpregnated lapping plates.

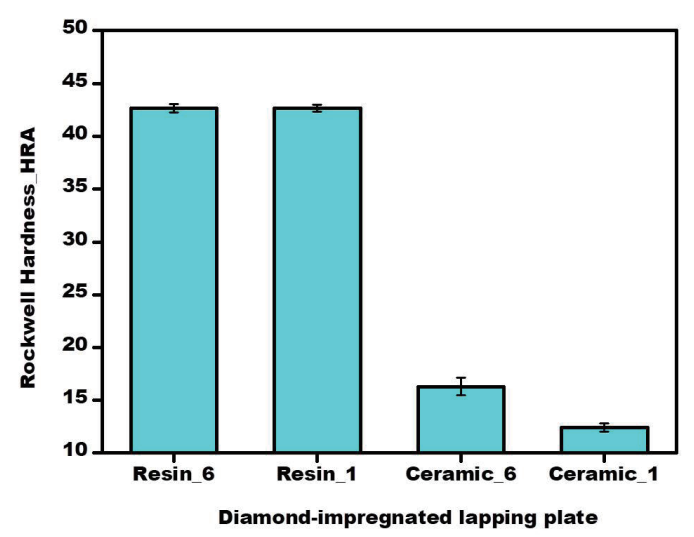

Fig. 6. (Color online) HRA of diamond-impregnated lapping plates.

understand this large difference in dressing rate, the Rockwell hardness and surface structure of the different lapping plates were investigated. Figure 6 shows the variation in the Rockwell hardness (HRA) of the four plates. Analysis showed that the HRA of the ceramic binder pads was in the range of 12-17, which is much lower than that of the resin bound pads, 42-43. The HRA of the compact resin-bonded lapping plates is 2.7 times that of the more porous ceramic plates, and this difference in hardness results in the dressing rate of the resin lapping plates being $47 \%$ lower than that of the ceramic plates. SEM images of the different diamond pads are shown in Fig. 7. It is very clear that there are no holes in the resin between the diamond grains in the resin-bound pads [Figs. 8(a) and 8(b)], whereas the ceramic pads are porous, as shown in Figs. 8(c) and 8(d). The porous structure of the ceramic binder (and the resulting difference in hardness) may explain why the dressing rate of the ceramic-bound pads is so different from that of the resin-bound pads. 


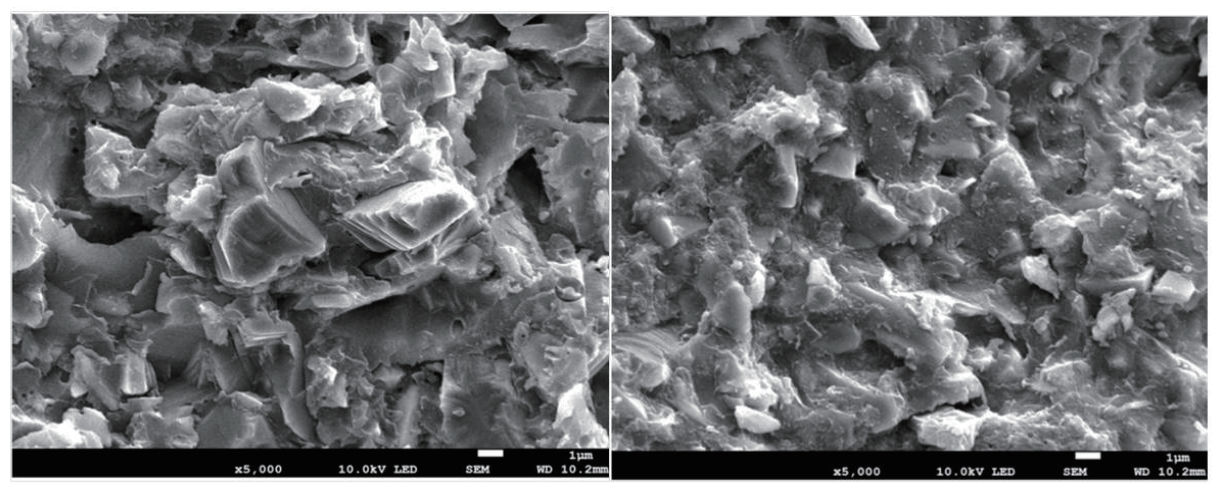

(a)

(b)

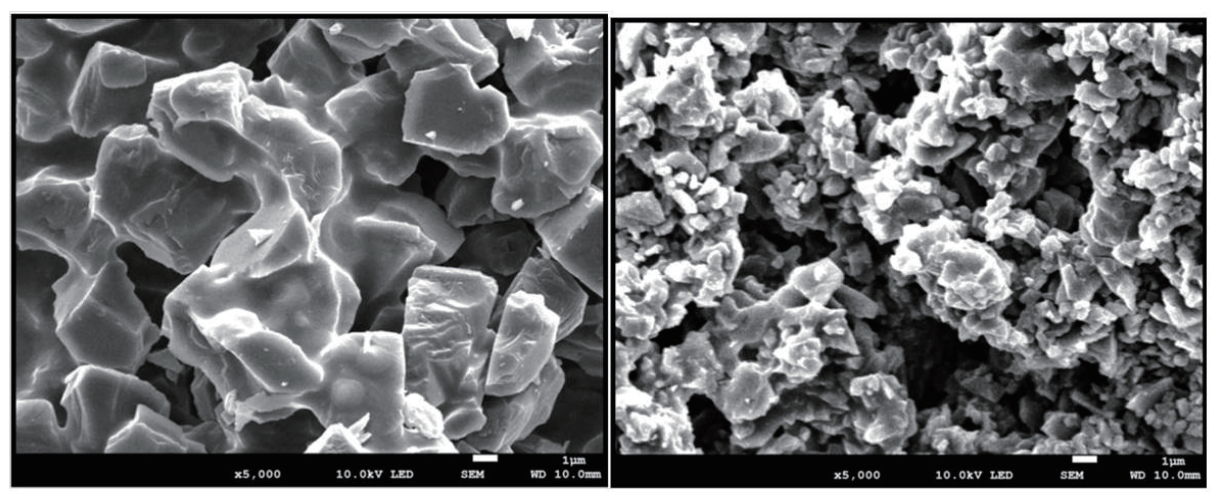

(c)

(d)

Fig. 7. FE-SEM images of combined impregnated lapping plate pads: (a) Resin_6, (b) Resin_1, (c) Ceramic_6, and (d) Ceramic_1.

\subsection{Material removal rate and grinding ratio of $\mathrm{SiC}$ wafer}

Figure 8 shows the material removal rates of silicon carbide achieved using the different diamond lapping plates at the same rotation speed and pressure. The material removal rate is defined as the thickness removed in units of time. The figure shows that the material removal rates for the lapping plates with pads bound by the ceramics were 67.34 and $10.86 \mu \mathrm{m} / \mathrm{h}$, for 6 and $1 \mu \mathrm{m}$, respectively. This is clearly higher than those for the pads with the same grit size bound by resin, which were about 4.91 and $2.35 \mu \mathrm{m} / \mathrm{h}$. An interesting observation was that the material removal rate with Ceramic_6 was 14 times higher than that with Resin_6. This is because the porous nature of the ceramic binder allowed more self-sharpening and the freshly exposed diamond grit increased the cutting efficiency (see Fig. 9). On the other hand, the resin wheel binder holds the diamond grit so strongly that there is little self-sharpening (see Fig. 10). This will reduce cutting ability and may even cause the deterioration of the workpiece surface. Grinding wheel wear is generally correlated with the amount of workpiece material ground, represented by a parameter called the grinding ratio $\left(W_{r}\right)$ defined as

$$
W_{r}=V_{w} / V_{m},
$$




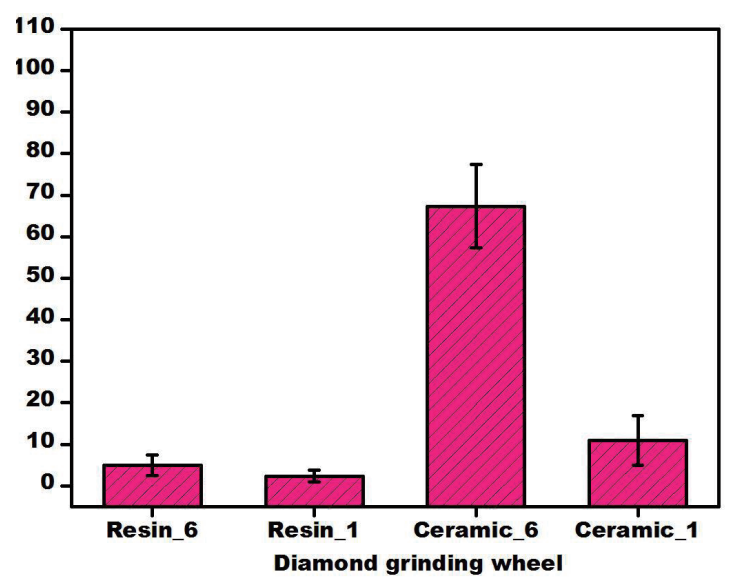

Fig. 8. (Color online) Silicon carbide material removal rate.

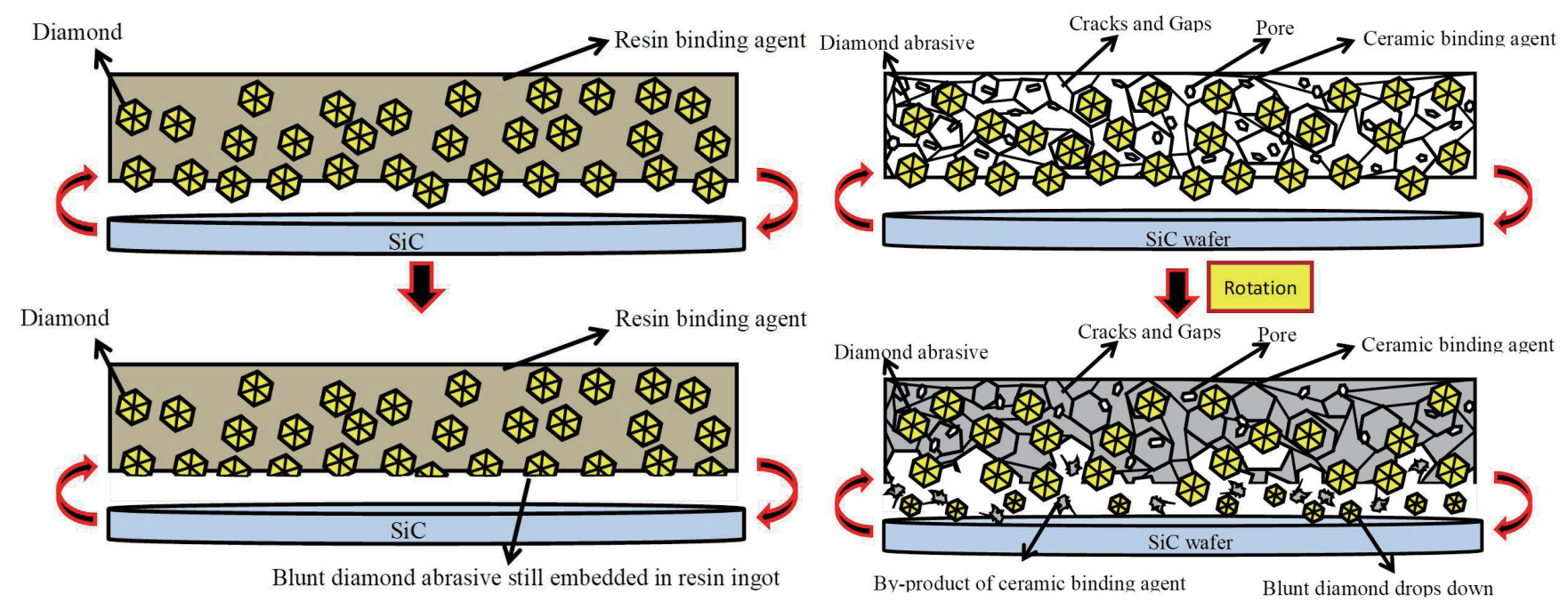

Fig. 9. (Color online) Removal mechanism of resinimpregnated lapping pads.

Fig. 10. (Color online) Removal mechanism of ceramic-impregnated lapping pads.

where $V_{m}$ is the volume of material removed and $V_{w}$ is the volume of wheel wear. In practice, the grinding ratio varies widely, ranging from 2 to 200 or ever higher, depending on the type of wheel, workpiece, and process parameters. Figure 11 shows the variation in the wheel grinding ratio for different diamond lapping pads. As can be seen in the figure, the grinding ratios achieved with Ceramic_6 and Ceramic_1 are approximately 3.1 and 4.3, respectively. Those values are clearly higher than those of Resin_6 and Resin_1, which are approximately 0.08 and 0.12. In practice, a higher grinding ratio is not always desirable and implies that consumption of the grinding wheel is the chief concern. In such a case, the use of resin as a binder would be recommended. However, the grinding ratio in the resin-bonded lapping pads is less than 1 because the wheel binder is very strong. This means that worn out diamond grit particles are held in place by the resin and new sharp points are not be exposed. The retention of the blunt diamond grit results in rubbing, rather than a cutting action, and the material removal rate will decrease. 


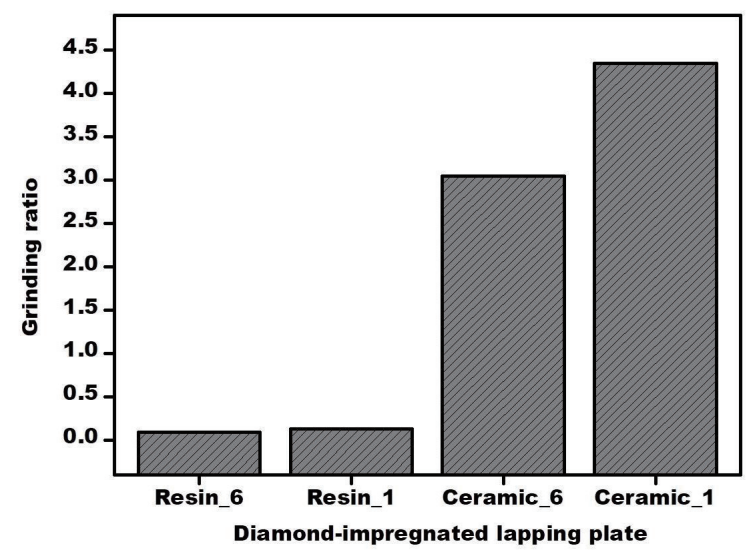

Fig. 11. Grinding ratio of diamond-impregnated lapping plates.

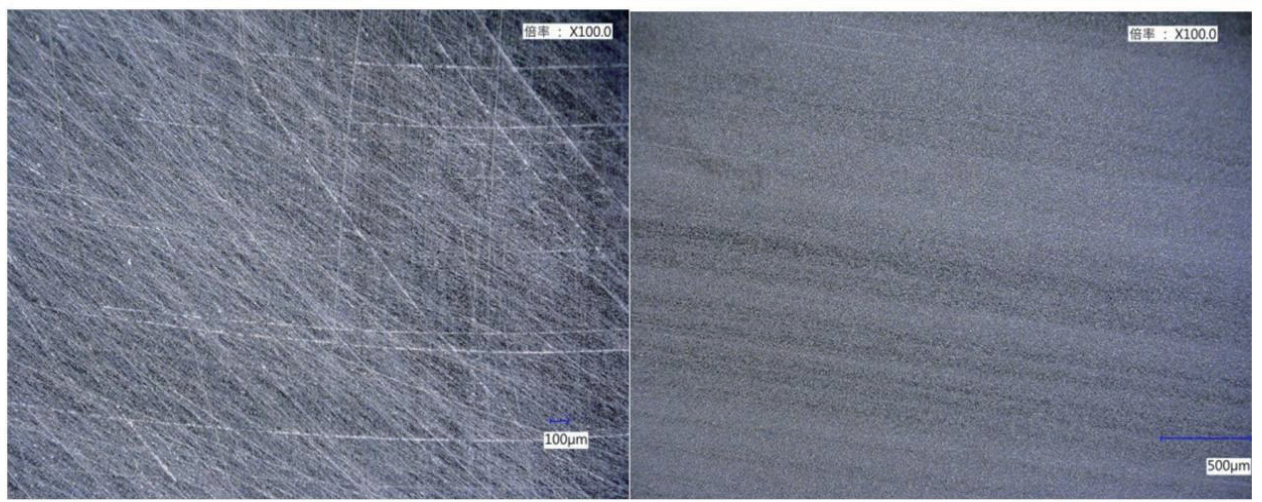

(a)

(b)

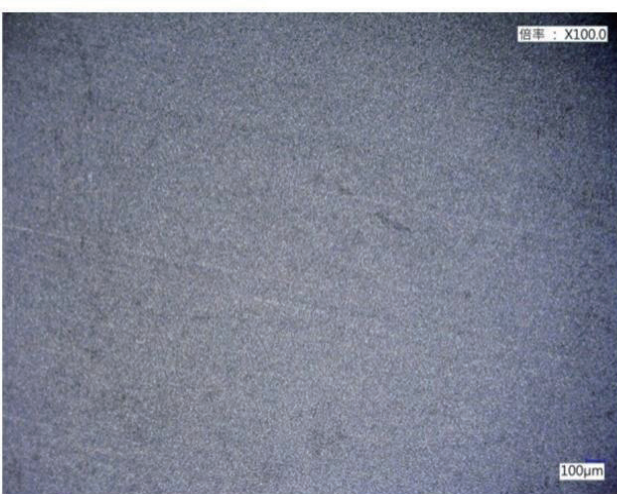

(c)

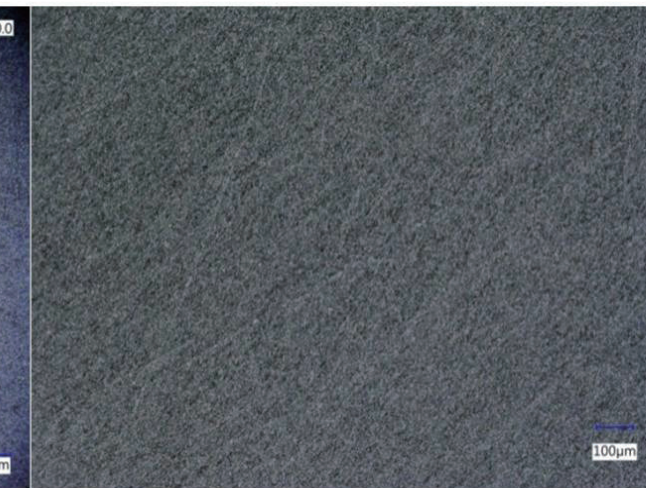

(d)

Fig. 12. (Color online) Surface structure of lapped silicon carbide wafers: (a) Resin_6, (b) Resin_1, (c) Ceramic_6, and (d) Ceramic_1.

Optical micrographs of the surfaces of $\mathrm{SiC}$ wafers after 30 min of lapping with the four different lapping plates are shown in Fig. 12. It can be seen that the surface of the wafer lapped using the Resin_6 plate has a large number of coarse scratches. The surface of the wafer lapped with Ceramic_6 shows much finer scratches. The diamond abrasive is more tightly bound by 


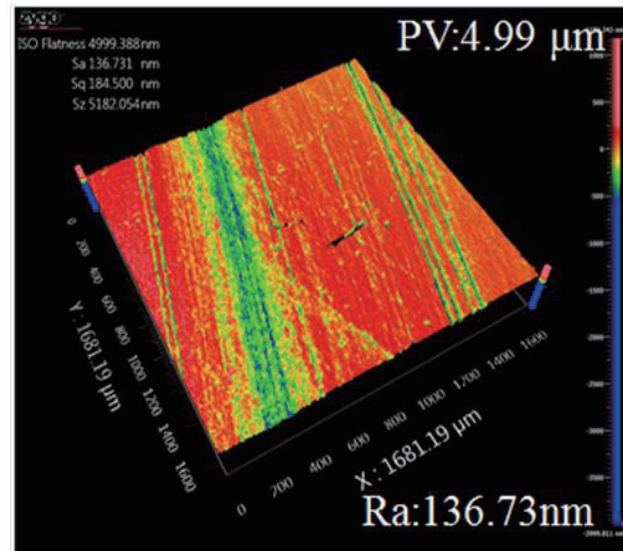

(a)

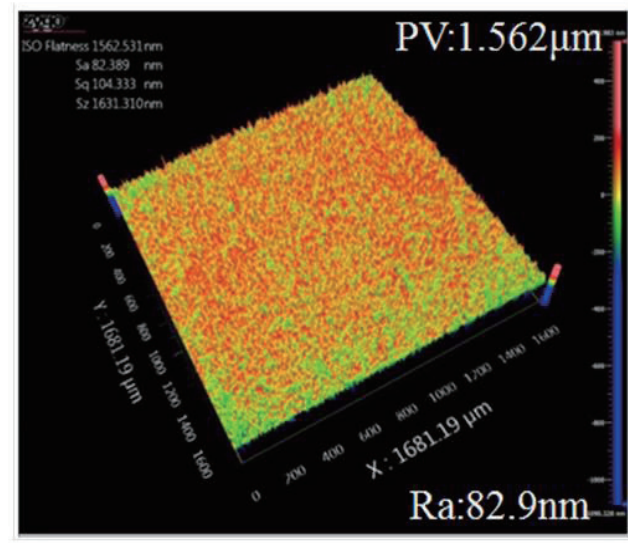

(c)

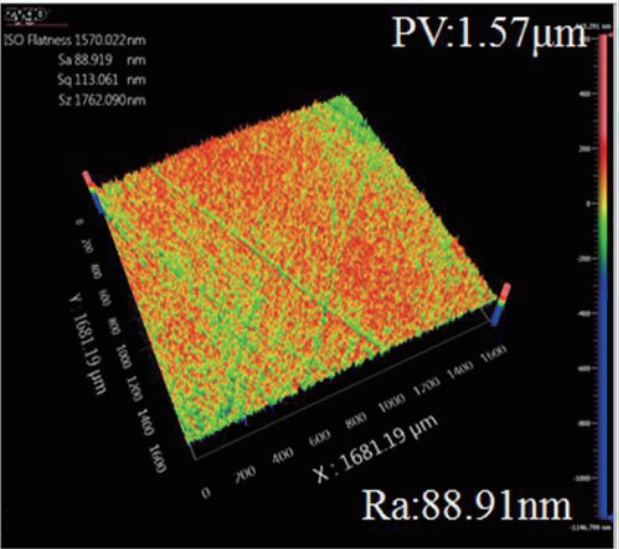

(b)

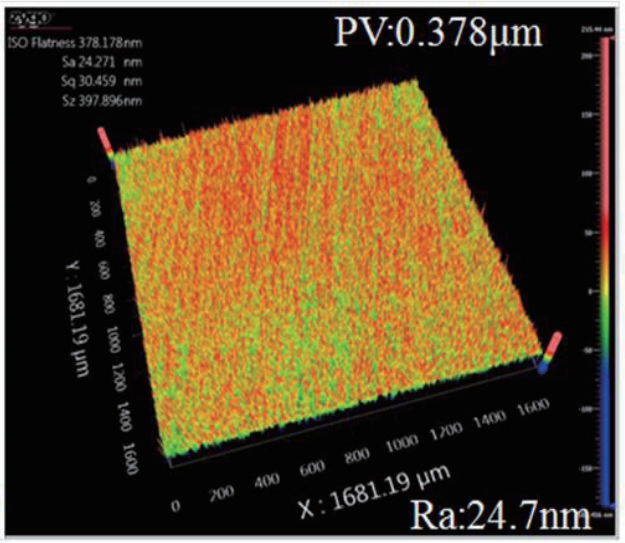

(d)

Fig. 13. (Color online) Surface roughness of lapped SiC wafers: (a) Resin_6, (b) Resin_1, (c) Ceramic_6, and (d) Ceramic_1.

resin and blunt diamond grit particles do not come loose and hence, there is more scratching. Both Resin_1 and Ceramic_1 plates produce far less scratching. A ZYGO 3D profiler was used to measure surface roughness, and the images are shown in Fig. 13. The surface of the wafer lapped with Resin_6 is much rougher than that produced using Ceramic_6. With Resin_6, Ra is about $136.73 \mathrm{~nm}$ and $P V$ is about $4.99 \mu \mathrm{m}$. With Ceramic_6, $R a$ is about $82.90 \mathrm{~nm}$ and $P V$ is about $1.56 \mu \mathrm{m}$. The surface produced by lapping with Ceramic_1 had an $R a$ of about $24.70 \mathrm{~nm}$ and a $P V$ of about $0.378 \mu \mathrm{m}$. These are markedly lower than the $R a$ of about $88.91 \mathrm{~nm}$ and the $P V$ of about $1.57 \mu \mathrm{m}$ achieved with Resin_1. Clearly, the reason for these differences is that the ceramic pads have better self-sharpening ability.

\section{Conclusions}

We presented a diamond grinding wheel for $\mathrm{SiC}$ to improve the material removal rate. On the basis of the experimental result, we list some conclusions below. 
(1) The dressing rate of the resin-impregnated lapping plate Resin_6 was $1.4 \mu \mathrm{m} / \mathrm{min}$ and for Resin_1 it was $0.6 \mu \mathrm{m} / \mathrm{min}$. The dressing rate of ceramic-impregnated lapping plate Ceramic_6 was $2.7 \mu \mathrm{m} / \mathrm{min}$ and for Ceramic_1 it was $0.8 \mu \mathrm{m} / \mathrm{min}$. Compared with the diamond abrasive size of $6 \mu \mathrm{m}$, it was found that the dressing rates of wheels bound by ceramic were about 2 times higher than those of wheels bound by resin owing to their porous structure.

(2) The material removal rate for the Resin_6 plate was $4.91 \mu \mathrm{m} / \mathrm{h}$ and for the Resin_1 plate, $2.35 \mu \mathrm{m} / \mathrm{h}$. The ceramic plates, on the other hand, showed much higher removal rates: for Ceramic_6 it was $67.34 \mu \mathrm{m} / \mathrm{h}$ and for Ceramic_1, $10.86 \mu \mathrm{m} / \mathrm{h}$. The removal rate achieved with ceramic plates was 14 times higher than that with resin plates. The very strong binding by the resin held the diamond grit particles so strongly that even after they had been blunted, they remained in place and continued to rub against the $\mathrm{SiC}$ surface without cutting. Thus; the removal rate decreased. On the other hand, the ceramic plate structure was porous and this allowed efficient self-sharpening. The blunt diamond grit broke away and fresh sharp points and edges were exposed. Lapping was more efficient and the abrasive surface remained sharp and in good condition, resulting in a high material removal rate.

(3) There was a great difference in the grinding ratio between the resin-bound plates and the ceramic plates. For Resin_6 and Resin_1, they were 0.08 and 0.12 . For Ceramic_6 and Ceramic_1, they were 3.1 and 4.3. In other words, the increase in material removal rate was accompanied by a much higher lapping plate consumption. The shorter working life of the ceramic lapping plates is a problem that needs to be solved.

(4) The tenacious hold that the resin has on the diamond grit particles means that more blunt grit particles remain in contact with the $\mathrm{SiC}$ surface during lapping. This causes excessive friction and scratching. The roughnesses of the $\mathrm{SiC}$ surfaces produced by lapping with Resin_6 and Resin_1 plates were 136.7 and $88.9 \mathrm{~nm}$. The surface roughnesses achieved with the Ceramic_6 and Ceramic_1 plates were 82.9 and $24.7 \mathrm{~nm}$. The excellent self-sharpening ability of the ceramic plates resulted in uniform material removal with the least rough surface. In fact, Ceramic_1 yielded an outstanding result in line with priority development objectives.

The ceramic-combined lapping plates have several benefits such as a high material removal rate, a high grinding ratio, and an excellent surface finish. The impregnated lapping plate can be of great value to the semiconductor industry.

\section{Acknowledgments}

The authors would like to thank the Ministry of Science and Technology, R.O.C., for financial support of this research under Contract No. MOST-105-2221-E-167-005-.

\section{References}

1 A. Harsha and U. Tewari: Polym. Test. 22 (2003) 403. https://doi.org/10.1016/S0142-9418(02)00121-6

2 F. Huo, D. Guo, R. Kang, and G. Feng: Trans. Nonferrous Met. Soc. China 22 (2012) 3027. https://doi. org/10.1016/S1003-6326(11)61566-5 
3 S. Gao, R. Kang, Z. Dong, and B. Zhang: Int. J. Mach. Tools Manuf. 64 (2013) 31. https://doi.org/10.1016/ j.ijmachtools.2012.08.002

4 B. Chen, B. Guo, and Q. Zhao: Proc. Inst. Mech. Eng., B 223 (2015) 65. https://doi. org/10.1177/0954405416656908

5 H. Kim, G. Park, Y. Seo, D. Moon, B. Cho, and J. Park: Wear 332 (2015) 794. https://doi.org/10.1016/ j.wear.2015.02.029

6 P. Velden: Microelectron. Eng. 50 (2000) 41. https://doi.org/10.1016/S0167-9317(99)00262-2

7 T. Enomoto, U. Satake, T. Fujita, and T. Sugihara: CIRP Ann. 62 (2013) 311. https://doi.org/10.1016/ j.cirp.2013.03.011

8 K. E. Puttick, M. R. Rudman, K. J. Smith, A. Franks, and K. Lindsey: Proc. Math. Phys. Eng. Sci. 426 (1989) 19. https://doi.org/10.1098/rspa.1989.0116

9 T. G. Bifano, T. A. Dow, and R. O. Scattergood: Am. Soc. Mech. Eng. 113 (1991) 184. https://doi.org/10.1115 / 1.2899676

10 M. R. Oliver, R. E. Schmidt, and M. Robinson: Electrochem. Soc. Proc. 26 (2000) 77. https://books.google. com.tw/books?hl=zh-TW\&lr=\&id=s0CnjLHD9PYC\&oi=fnd\&pg=PA77\&dq $=$ doi $+\mathrm{CMP}+$ pad + surface + ro ughness + and $+\mathrm{CMP}+$ removal + rate\&ots $=$ UxEaKlqPDO\&sig=YxSYuy6Pu_QaI5jqG0k-bWhcICs\&redir $\mathrm{esc}=\mathrm{y} \# \mathrm{v}=$ onepage $\& \mathrm{q} \& \mathrm{f}=$ false

11 Z. Zhang, Y. Song, C. Xu, and D. Guo: Scri. Mater. 67 (2012) 197. https://doi.org/10.1016/j.scriptamat.2012.04.017

\section{About the Authors}

Ming-Yi Tsai received her B.S. degree from National Taiwan University of Science and Technology, Taiwan, in 1993 and her M.S. and Ph.D. degrees from National Taiwan University in 2000 and 2006, respectively. From 2007 to 2011, she was an assistant professor at National Chin-Yi University of Technology, Taiwan. Since 2011, she has been a professor at National Chin-Yi University of Technology, Taiwan. Her research interests are in cutting, grinding, and polishing technology. (mytsai@ncut.edu.tw)

Yue-Feng Lin received his B.S. degree from National Cheng-Kung University, Taiwan, in 2008 and his M.S. and Ph.D. degrees from National Cheng-Kung University, Taiwan, in 2009 and 2016, respectively. From 2017 to 2018, he was a postdoctoral researcher at National ChinYi University of Technology, Taiwan. His research interests are in difficult-to-cut materials machining and finishing. (yuefenglin750701@gmail.com)

Guan-Fu Lin received his B.S. and M.S degrees from National Chin-Yi University of Technology, Taiwan, in 2015 and 2017, respectively. His research interests are in diamond grinding and lapping. (tofu8165@gmail.com) 